\title{
EDUCAÇÃO JURÍDICA: NA EDUCAÇÃO INFANTIL E ENSINO FUNDAMENTAL
}

\author{
ELOISIO JORDÃO DA SILVA* \\ Gustavo COTOMACCI **
}

\section{RESUMO}

O presente artigo pretende analisar a necessidade da inclusão da educação jurídica na matriz curricular da Educação Infantil e Ensino Fundamental. Para tanto, foi utilizada pesquisa literária que verse sobre a temática em questão, bem como todo tipo de acervo científico disponível e tomando como coluna principal o viés de alguns doutrinadores que já discorreram sobre o assunto. Objetivando a inclusão da educação jurídica e mais precisamente, o ensino dos direitos fundamentais elencados na nossa Carta Magna, por meio de uma educação reflexiva, permitindo que educador e educando utilizem suas habilidades ao problematizarem a disciplina estudada, para melhor adaptá-la à vida contemporânea, tendo sempre em vista a prática. Pretendendo obter o resultado de um cidadão que ao longo de sua aprendizagem escolar, fora instruído à educação jurídica necessária para exercer de forma plena suas atividades enquanto cidadão, que conscientizado de seu lugar no mundo atua efetivamente como agente transformador nas tomadas de decisões de seu país e, consequentemente, se for preciso, sabe como utilizar seu intelecto jurídico para evitar a opressão de um governo ditatorial por meio de uma sociedade livre, atuante e democrática que busca viabilizar a garantia da justiça e a equidade como premissa de um Estado democrático.

Palavras-chave: Educação Jurídica; Cidadania; Democracia; Justiça; Direitos Fundamentais.

\section{LEGAL EDUCATION: CHILDREN'S EDUCATION AND FUNDAMENTAL EDUCATION}

\section{ABSTRACT}

This article aims to analyze the need for the inclusion of legal education in the curriculum of Early Childhood and Elementary Education. For this purpose, literary research was used that deals with the subject in question, using all kinds of available scientific collection and taking as a main column the bias of some doctrines who have already discussed the subject. Aiming at the inclusion of legal education and more precisely, the teaching of fundamental rights listed in our Magna Carta, through a reflective education, allowing educator and student to use their skills when problematizing the studied discipline, to better adapt it to life contemporary, always with a view to practice. Intending

* Bacharel em Direito pela Universidade Metodista de São Paulo UMESP. Graduado em 12/2020 e-mail: eloisio7@hotmail.com

** Mestre em Educação pela Universidade Metodista de São Paulo. Especialista em Direito Constitucional pela Escola Superior de Direito Constitucional - ESDC. Advogado. Professor Universitário. Coordenador do curso de Direito na Universidade Metodista de São Paulo. 
to obtain the result of a citizen who, throughout his school learning, had been instructed in the legal education necessary to fully exercise his activities as a citizen, who, aware of his place in the world, effectively acts as a transforming agent in the decision-making of his country and, consequently, if necessary, he knows how to use his legal intellect to avoid the oppression of a dictatorial government through a free, active and democratic society that seeks to make possible the guarantee of justice and equity as the premise of a democratic state. Keywords: Legal Education; Citizenship; Democracy; Justice; Fundamental rights.

\section{INTRODUÇÃO}

O presente trabalho tem o condão de analisar a necessidade de uma disciplina jurídica na matriz curricular da Educação Infantil e Ensino Fundamental para que, desde o início da formação do indivíduo/ser humano, este, em suas experiências pessoais e indivisíveis, ao longo do caminho que se percorre para poder participar de forma efetiva enquanto cidadão, tenha a oportunidade de conhecimento e contato direto com uma base jurídica.

$\mathrm{O}$ artigo tem o fim de mensurar a importância da base jurídica (Direitos Fundamentais) para o aperfeiçoamento do indivíduo até o exercício de sua cidadania para a fruição da capacidade civil e política, e se com tal estrutura jurídica haverá a transformação de cidadãos mais aptos a reivindicarem seus direitos e participarem de forma efetiva, permanente e eficaz nas tomadas de decisões de sua nação. Transformando-se em cidadão que com clareza percebe quando seus direitos são burlados e em qual direção está caminhando seu país.

É com a inserção do ensino jurídico nas unidades educacionais que se pretende/objetiva o aperfeiçoamento do indivíduo, para que este, quando chegar ao pleno gozo de exercer seus direitos civis e políticos, o exerça e reivindique de forma clara e consciente.

Por meio de pesquisa científica literária de autores que já estudaram sobre a educação jurídica, sua importância no desenvolvimento do indivíduo e como esse conhecimento pode ajudar na formação de um cidadão apto para o exercício de seus direitos e obrigações é que verificaremos a relevância ou não de determinada temática com suas posteriores consequências na época contemporânea.

No decorrer do artigo será analisado se, com a base jurídica pretendida, o indivíduo reivindicará por seus direitos, mesmo que lhes sejam negados e se ao passo de tal conhecimento haverá a transformação de um indivíduo em um cidadão que de fato exerça seus direitos com viés na evolução da sociedade.

\section{EDUCAÇÃO JURÍDICA E SEU INÍCIO NO BRASIL}

O ensino da disciplina jurídica tem início com o fim da colônia portuguesa. Com a independência do Brasil em 07 de setembro de 1822, surge a necessidade que o país crie suas próprias leis, pois era regido pelas leis Portuguesas, tendo seu escopo jurídico praticamente em Coimbra. 
Surgem então dois cursos em 11 de agosto de 1827, de Ciências Jurídicas e Sociais, um no município de São Paulo e outro no município de Olinda. O curso além da intenção do ensino jurídico tem como finalidade a formação de políticos, iniciando suas atividades em 1828.

Seu objetivo principal é a formação de advogados e políticos para atender a necessidade da jovem pseudoliberdade, que conquistará, se perfazendo na história por inúmeros acontecimentos políticos, econômicos, sociais e culturais.

Sua real mudança acontece em 1994 como nos pontua Cotomacci (2017, p. 37) "Ocorre que, passado por todas essas oscilações, o ensino jurídico sempre se pautou pelo mesmo paradigma; somente começaram a ocorrer mudanças significativas em 1994, de acordo com a Portaria 1.886 do MEC".

A Portaria 1.886/94 abrange mudanças significativas, contudo, deixa à margem a sala de aula, fazendo com que os alunos apenas absorvam conhecimento sem a mínima reflexão, entretanto, se observa a tentativa de quebrar esse método de ensino, onde o aluno é apenas um ouvinte sem a possibilidade de uma reflexão do assunto em questão, tentando fazer a junção do que de fato deu certo no passado, com a necessidade didática presente, fazendo com que o aluno tenha a possibilidade de questionamento e reflexão.

O ensino jurídico se inicia de forma rígida e não só a disciplina do Direito, mas todas as outras disciplinas que vieram tiveram sua base com uma metodologia ditatorial, em que o professor é apenas o expositor oral do conteúdo do acervo de livros que compunha tal instituição. Mesmo assim, podemos enxergar um ponto negativo e um ponto positivo.

Temos nesse início rígido, sedimentado, o começo da educação, ainda que de forma ditatorial (ponto negativo) e é com essa base ao longo da história que podemos pontuar a postura do docente e a necessidade de reflexão (ponto positivo) entre aluno e professor.

A história nos mostra a necessidade de mudança na metodologia de ensino, desta forma o aluno não será mais um ouvinte inerte que apenas reproduz o conhecimento que lhe foi passado, mas, que pensa, questionando e interagindo com o conhecimento apropriado para mudar o mundo e, indispensavelmente evoluindo para o futuro.

É preciso uma mudança na forma de pensar o Direito, não sendo mais uma disciplina apenas reservada aos técnicos do Direito, esse conhecimento deve mudar a vida social, gerando novos valores que transformarão a população.

A finalidade é fazer com que a população resolva seus conflitos buscando o Direito de forma pacífica para a solução das lides, isso de maneira natural e, com a reflexão do conhecimento jurídico seja transformado o meio social. 
invés de ser entendida como uma forma de pacificação e, ao derrotado, compreender e assumir seus erros. (COTOMACCI, 2017, p. 41).

Assim como na Grécia Antiga, o Direito era algo inato ao cidadão, apropriando-se do conhecimento jurídico com naturalidade, sabendo como aplicá-lo, dispensando a figura do advogado:

Tomando-se como base a concepção da Grécia Antiga, é compreensível o brocardo jurídico ubi societas ibi jus (não existe sociedade sem direito) e ubi jus ibi societas (não existe direito sem sociedade), sendo que os membros da sociedade (em uma concepção contemporânea) fazem parte de um Estado, não mais como a concepção na antiguidade de uma família, casta ou a um indivíduo. (COTOMACCI, 2017, p. 42).

A relação entre cidadão e Estado é regida pela norma jurídica independentemente de sua época e a lei deve ser usada para harmonia social de maneira pacífica, surgindo um cidadão transformado pela norma e que de forma inerente a respeita, propagando-a no seio da sociedade.

Entretanto, o que vemos é o medo do poder coercitivo da lei, que se infringida, trará consequências negativas ao infrator. E este apenas a utiliza como forma de ataque dentro das possibilidades que lhes são oportunizadas.

Contribui, sobremaneira, a falta de credibilidade no poder público, caindo em descrédito a lei, principalmente quando é infringida e manipulada por aqueles que deveriam servir de exemplo para a população.

O ensino jurídico se faz necessário, pois se evidencia de forma clara e notória seus princípios e diretrizes na vida cotidiana da sociedade, ficando evidente a importância deste ensino para que uma sociedade possa viver de forma harmônica e pacífica:

O ensino jurídico do cidadão torna-se notadamente necessário, pois presente estão as leis e princípios no seu dia a dia, nos seus afazeres mais corriqueiros, delimitando direitos e deveres, e cabe ao cidadão o discernimento em julgar e interpretar seus atos para que com isso a lei seja cumprida [...] (COTOMACCI, 2017, p. 42).

Vale ressaltar que a justiça será alcançada não apenas pelo ensino jurídico, mas, em conjunto de uma mudança cultural, em que, a sociedade possa sensibilizar-se pela lei ao ponto de amá-la e manifestá-la de forma espontânea.

Contudo, é a partir dos docentes que deve emergir essa sensibilidade que será transmitida aos discentes, e estes sem temer a lei, agora com um olhar renovado, a utilizarão de forma intrínseca à sua cultura sem o sentimento temerário do poder coercitivo da norma, empregando-a como base norteadora de harmonia para o Estado procurando aplicá-la com zelo: 
por ocasião, para completar a renda, faz com que um dos requisitos essenciais nessa missão deixe de estar presente, o eros, conforme Platão. (COTOMACCI, 2017, p. 45).

Como supramencionado, essa sensibilidade quanto à lei é transmitida pelos professores aos alunos, mas cabe salientar que muitos docentes acabam por lecionar na universidade apenas para complementar a renda ou apenas para ostentarem o status de professores acadêmicos, perdendo o foco da realidade e/ou do objetivo do ensino, que é transmitir o conhecimento com reflexão e, acima de tudo, com paixão e amor, para que esse conhecimento venha verdadeiramente transformar seu detentor e as pessoas que vivem ao seu derredor.

Permitindo, com isso, a transformação do Estado na sua totalidade, galgando patamares maiores no futuro pela renovação do conhecimento. "Entretanto, só é possível com uma consciência docente do seu papel perante os seus alunos, uma sensibilidade capaz de notar o poder das palavras proferidas, e que o ser professor é carregado por toda a vida, dos bons docentes e dos ruins". (COTOMACCI, 2017, p. 47).

É preciso repensar, trazer à mente que os alunos e professores não estão na universidade apenas para sua projeção profissional através do conhecimento ou, do status de um diploma na vida profissional, é necessário que tal conhecimento mude o ambiente em que vivemos.

Até mesmo porque o conhecimento em questão impactará no tripé do desenvolvimento humano: desenvolvimento pessoal, estrutura para o exercício da cidadania e crescimento profissional.

Ademais, precisamos notadamente frisar a importância da docência, pois é nela que se inicia esse amor pelo conhecimento jurídico, com o viés de mudança e impacto na vida social, transmitindo uma paixão aos alunos que se perpetuará nas próximas gerações.

Desmistificando a concepção de que a lei beneficia apenas o rico, que a usa em detrimento do pobre. "O Direito no mundo e a forma como se lida com ele circunscrevem-se em uma manifestação cultural. Em um país como o Brasil, no qual a ideia de que as leis só favorecem os mais ricos em detrimento dos mais fracos, torna-se uma barreira para o ensino jurídico". (COTOMACCI, 2017, p. 48).

Sim, é com o conceito de um conhecimento jurídico reflexivo, combativo e apaixonado pela própria lei que esta transformará e desenvolverá a população, preparando-a para o exercício da cidadania e qualificando a pessoa para a sua vida profissional.

Só com a sensibilidade de ambos, docente e discente, ao entender que o conhecimento deve ser reflexivo e não apenas um conteúdo inerte depositado no ouvinte, sim, se faz necessário um olhar diferente ao modo de transmitir o ensino jurídico, quebrando as barreiras da cultura contemporânea e projetando uma cultura de que é necessário o conhecimento da norma jurídica como fonte pacificadora, sendo esta, sem distinção de classe social, que os levará a justiça. 
Segundo Cotomacci (2017, p. 41) "Os estudantes não têm um desdobramento reflexivo do Direito, vivem sem perceber, cabe um desenvolvimento pedagógico para o despertar dos alunos, no sentido de desvelar o valor do Direito na vida".

Necessário à projeção de uma nova cultura que entenda de forma intrínseca que a sociedade não vive sem a lei e esta é o alicerce para o pleno exercício da democracia e cidadania.

\section{O DIÁLOGO NA EDUCAÇÃO}

No presente trabalho levantamos a hipótese de que o diálogo entre professor e aluno se faz fundamental para o desenvolvimento de ambos, permitindo se aprofundarem na disciplina.

Assim como se apresenta a crítica com o termo "educação bancária"(FREIRE, 1987), este trabalho verifica que o ensino não deve ser apenas encher o aluno de conhecimento, mas dar-lhe a oportunidade para criticar e/ou argumentar, possibilitando o crescimento de ambos.

Desta forma, se compreende a educação bancária, em que o educador é o depositante e o educando o depositário. Sem que haja uma interação, sem nenhuma reflexão, apenas uma memorização do conhecimento transmitido, não havendo nenhuma interação reflexiva sobre o ensino.

Na concepção da educação bancária o que apenas vislumbramos é o silêncio do educando, ante a voz suprema do educador que vai se perpetuando como o ser que detêm o conhecimento e o educando, que nada sabe, não pode indagar ou refletir sobre o conhecimento transmitido, contudo, apenas deve em sinal de obediência, ouvir e, mais uma vez ouvir:

\footnotetext{
Esta concepção "bancária" implica, além dos interesses já referidos, em outros aspectos que envolvem sua falsa visão dos homens. Aspectos ora explicitado, ora não, em sua prática. Sugere uma dicotomia inexistente homens-mundo. Homens simplesmente no mundo e não com o mundo e com os outros. Homens espectadores e não recriadores do mundo. Concebe a sua consciência como algo especializado neles e não aos homens como "corpos conscientes". (FREIRE, 1987, p. 36).
}

Assim, o papel do educador não é mais apenas reproduzir o que aprendeu em seu acervo literário para que os educandos apenas memorizem, mas, com um dialogismo entre educador-educando, ambos, estão em um contínuo processo de interação, criticando e pensando em comunhão dentro do processo de conhecimento. Destarte, ambos estão educando e sendo educados simultaneamente.

Com a educação problematizadora, dialógica, reflexiva e mediatizados pelo mundo os homens paulatinamente, na medida de seu conhecimento, começam a passar pelo processo de desalienação e, por conta deste, passam a reconhecer o mundo e seu lugar no mundo. 
A educação problematizadora prioriza a vida, a liberdade e o reconhecimento do próprio educando e de seu lugar no mundo. Com a evolução contínua da sociedade, permitindo a desalienação do homem e tirando as amarras da opressão.

\section{A IMPORTÂNCIA DA CORRELAÇÃO ENTRE AS DISCIPLINAS}

A interdisciplinaridade é o termo empregado para caracterizar a relação existente entre uma disciplina e seus diversos setores, por exemplo, como o Direito se relaciona com outras disciplinas, seu impacto social, econômico, político etc.

Sua característica é a relevante troca de informações no que tange aos diversos setores de uma mesma ciência, visando seu enriquecimento mútuo.

A interdisciplinaridade é um saber unificado que permitirá, de forma crítica e reflexiva, o aprofundamento da disciplina estudada, fazendo a conexão desde a formação escolar até a atividade profissional. Sua premissa é substituir o enfoque da disciplina e elencar a verdade do homem enquanto ser no mundo.

Nessa correlação entre as disciplinas permite-se que cada uma seja enriquecida pela troca mútua do conhecimento entre elas:

Interdisciplinaridade é um termo utilizado para caracterizar a colaboração existente entre disciplinas diversas ou entre setores heterogêneos de uma mesma ciência (exemplo: Psicologia e seus diferentes setores: Personalidade, Desenvolvimento Social etc.). Caracteriza-se por uma intensa reciprocidade nas trocas, visando a um enriquecimento mútuo. (FAZENDA, 2011, p. 73).

O objetivo é preparar os alunos a pesquisarem, correlacionando os estudos com outras áreas acadêmicas, desta forma entendendo a conexão entre as disciplinas.

Ademais, a interdisciplinaridade não tem o condão de ficar apenas no campo da teoria, mas, se faz indispensável que haja a união da teoria e o campo prático (práxis), existindo a própria pesquisa na prática, na vida cotidiana da sociedade, assim sendo, a interdisciplinaridade, é também a unificação dos dois polos (teoria e prática).

A integração é uma necessidade funcional em que o indivíduo em contato com a realidade vai adquirindo sua experiência e conhecimento (integrado ao mundo) antes da interdisciplinaridade, sendo assim, essa interatividade não é compreendida como algo acabado, mas sim, uma das etapas a ser transcorrida.

Os alunos devem aprender como as demais ciências se relacionam com a educação jurídica desde exatas, português, geografia, arte, história, cultura etc.

\section{EDUCAÇÃO JURÍDICA: NA EDUCAÇÃO INFANTIL E ENSINO FUNDAMENTAL}

O conhecimento dos direitos fundamentais básicos é inerente à formação do indivíduo enquanto percorre o caminho para se tornar um pleno cidadão apto para o exercício da cidadania garantindo o direito efetivo à justiça. 
Sendo o direito o meio para se alcançar a justiça, nada mais justo que desde a formação escolar da Educação Infantil e Ensino Fundamental, cada sujeito de direito (pessoa) possa começar a ter acesso ao conhecimento jurídico básico como, por exemplo: direitos fundamentais, os três poderes, a soberania, direitos políticos etc.

Dentro deste viés é importante se perguntar: seria adequado inserir uma disciplina de direitos fundamentais; os poderes, a soberania e os direitos políticos na matriz curricular da Educação Infantil e Ensino Fundamental?

Este estudo trabalha com a hipótese que seria sim, de suma importância, a educação jurídica nas escolas. Até mesmo pela relevância da matéria e o papel do cidadão no desenvolvimento de seu país, desta forma também garantindo a cada cidadão o direito à justiça.

O ensinamento jurídico na matriz curricular é imprescindível no desenvolvimento de cada indivíduo, até que ele alcance o pleno exercício da cidadania:

Ter acesso às informações jurídicas é de vital necessidade para o cidadão, porque para o exercício da cidadania é de suma importância que este tenha, pelo menos, noções de Direitos Humanos, noções de Direitos Fundamentais e noções de Cidadania, pois sem tais informações ele não será capaz de desenvolver-se como cidadão de direitos e deveres perante o Estado e a sociedade. (OLIVEIRA, 2013, p. [2]).

A sociedade faz parte na formação de cada pessoa natural seja de forma direta ou indireta e o Estado em conjunto com a sociedade solidariamente, ambos atuam de igual modo no pleno desenvolvimento de cada cidadão.

Sendo assim, a sociedade diretamente atua quando um ente familiar custeia o ensino particular para um dos integrantes de sua família e indiretamente quando cada cidadão paga os seus impostos, que também tem o condão de ser administrado e direcionado certa parcela desses mesmos impostos à Educação pelo Estado.

Como bem nos preceitua a Constituição no seu artigo $1^{\circ}$ "a República Federativa do Brasil, formada pela união indissolúvel dos Estados e Municípios e do Distrito Federal, constitui-se em Estado Democrático de Direito e tem como fundamentos: II - a cidadania; [...]" (BRASIL, 1988). Sendo regido dessa forma é preciso que o país propicie a instrução necessária aos cidadãos.

Ainda dentro deste mesmo viés e aproveitando o ensejo, nos direciona a Lei que estabelece as Diretrizes e Bases da Educação Nacional No 9.394 de 20 de dezembro de 1996 nos seguintes dizeres em seu artigo $1^{\circ}$.

A educação abrange os processos formativos que se desenvolvem na vida familiar, na convivência humana, no trabalho, nas instituições de ensino e pesquisa, nos movimentos sociais e organizações da sociedade civil e nas manifestações culturais. $\S 1^{\circ}$ Esta Lei disciplina a educação escolar, que se desenvolve, predominantemente, por meio do ensino, em instituições próprias. $\S 2^{\circ} \mathrm{A}$ educação escolar deverá vincular-se ao mundo do trabalho e à prática social. (BRASIL, Lei No 9.394/96). 
Vale lembrar que o acesso à Educação é salvaguardado pela Declaração Universal dos Direitos Humanos em seu artigo 26:

1. Toda a pessoa tem direito à educação. A educação deve ser gratuita, pelo menos a correspondente ao ensino elementar fundamental. O ensino elementar é obrigatório. O ensino técnico e profissional dever ser generalizado; o acesso aos estudos superiores deve estar aberto a todos em plena igualdade, em função do seu mérito. 2. A educação deve visar à plena expansão da personalidade humana e ao reforço dos direitos humanos e das liberdades fundamentais e deve favorecer a compreensão, a tolerância e a amizade entre todas as nações e todos os grupos raciais ou religiosos, bem como o desenvolvimento das actividades das Nações Unidas para a manutenção da paz. 3. Aos pais pertence a prioridade do direito de escholher o género de educação a dar aos filhos. (BRASIL, DECLARAÇÃO UNIVERSAL DOS DIREITOS HUMANOS, 1948 - grifo nosso).

A Constituição de 1988 trata da educação em seus artigos 205 a 214, podendo assim ser percebido que o acesso à educação além de ser um preparo para o pleno exercício da cidadania, lapida o próprio cidadão para o seu desenvolvimento profissional:

A educação jurídica é um complemento dos direitos fundamentais de um cidadão, tendo este, direitos e deveres perante o Estado. É por meio dela que se consegue uma melhor atuação de uma pessoa civil na democracia, de forma a contribuir com suas ideias e criticas nas demasiadas atuações do Estado. (OLIVEIRA, 2013, p. [4]).

Vale lembrar, para que cada cidadão tenha plena capacidade de atuar em um país democrático de direito, com base na cidadania, o Estado e a sociedade devem de todas as formas possíveis instruí-lo para o apto exercício de suas atividades enquanto cidadão.

Deste modo é imprescindível a inclusão do ensino jurídico na grade curricular da primeira infância e anos posteriores, pois tanto a sociedade quanto o Estado solidariamente são responsáveis na formação da pessoa natural, preparando o cidadão na luta consciente pela garantia da justiça e para exercer suas atividades eleitorais com plenitude, como cidadão consciente de deveres e direitos. Além do enriquecimento intelectual e profissional que tais conhecimentos jurídicos agregarão na carreira profissional.

Esta pesquisa concorda com a posição de Fernanda Godinho Franco (2019) na assertiva de outras disciplinas serem cabíveis na matriz da Educação como fora supramencionado para o desenvolvimento do cidadão, poderíamos citar como exemplo: as normas de trânsito, educação ambiental jurídica e inúmeras disciplinas que terão impacto na cultura, na economia e política de nosso país, levando em consideração a mudança social gerada por conta da conscientização destes futuros cidadãos.

Isso teria um impacto cultural e econômico: com a redução de acidentes e consequentemente no impacto ambiental. Nas palavras da autora: 
A título de exemplo, ressalta-se a importância de serem ensinadas as normas de trânsito em prol da cidadania. $\mathrm{O}$ trânsito envolve pedestre, passageiro, ciclista e demais condutores. Preparar culturalmente a sociedade para o trânsito é transformar a história em favor da preservação da vida, levando em conta o alto índice de acidentes por conta de falhas humanas. Nesse enfoque, é necessário frisar que a família deve exercer o seu papel, no sentido de inserir, aos poucos, as crianças no universo do trânsito. Com isso as falhas poderão ser menores. (FRANCO, 2019, p. [19]).

Com a inserção da disciplina jurídica do Direito Ambiental na matriz curricular, passaríamos a conscientizar e preparar as crianças e adolescentes sobre os danos causados na Biosfera pelo ser humano e, como minimizar tais consequências.

Ainda ao que tange à esfera do Direito Ambiental nos preceitua a Constituição Federal (BRASIL, 1988). em seu artigo 225: “Todos têm direito ao meio ambiente ecologicamente equilibrado, bem de uso comum do povo e essencial à sadia qualidade de vida, impondo-se ao Poder Público e à coletividade o dever de defendê-lo e preservá-lo para as presentes e futuras gerações".

No que tange à sociedade devemos priorizar até mesmo o ambiente familiar como meio de ensino, através dos responsáveis do menor em formação e, em parceria, a ação do Estado em propiciar as referidas disciplinas nas escolas inserindo-as na matriz da Educação Infantil e Ensino Fundamental.

\section{DIREITOS FUNDAMENTAIS: A ESSENCIA PARA O DESENVOLVI- MENTO DA CIDADANIA}

Em que pese falarmos no acesso à educação jurídica e isso com a inclusão de disciplinas jurídicas na matriz curricular e como premissa desse conhecimento os direitos fundamentais, cabe fazermos uma breve distinção entre Direitos Fundamentais e Direitos Humanos.

Ao elencarmos a palavra "Direito Fundamental", cabe salientar que no âmbito de direitos fundamentais estamos discorrendo sobre os direitos acolhidos através das convenções e tratados internacionais os quais foram positivados dentro da Constituição de cada Estado.

E toda vez que nossa Carta Magna se refere à comunidade internacional, está tratando dos Direitos Humanos. Ao passo que ao refletir sobre direitos humanos, cabe pensarmos nos direitos internacionais que nos aponta os requisitos mínimos para que a pessoa humana possa ser tratada de forma digna, minimamente falando, segundo o princípio da dignidade da pessoa humana.

Desta maneira os direitos fundamentais passaram a ser a base do escopo jurídico de cada Estado, sendo esta base o limite de atuação condicionado à Constituição Federal, sendo a organização do Poder e as competências delegadas aos Estados membros.

Dentro dessas competências estatais existem parâmetros e limites de certos valores e liberdades fundamentais, nos quais temos a ideia de Estado de Direito. 
Orienta-nos Sarlet (2012, p. 47) "o poder se justifica por e pela realização dos direitos do homem e que a ideia de justiça é hoje indissociável de tais direitos".

De acordo com o autor e com o que já foi explanado até o presente momento, os direitos fundamentais são a premissa nas disciplinas jurídicas a serem inclusas na matriz curricular da Educação Infantil e do Ensino Fundamental, pois carregam em seu bojo o conhecimento mínimo para defesa e liberdade de cada cidadão e como a sociedade pode portar-se para se libertar de um governo opressor ou, até mesmo, evitar que este chegue às vias da opressão.

Além de instrumentos de defesa, são os direitos fundamentais, elementos da ordem jurídica objetiva como discorre o doutrinador Sarlet:

É justamente neste contexto que os direitos fundamentais passam a ser considerados, para além de sua função originária de instrumentos de defesa da liberdade individual, elementos da ordem jurídica objetiva, integrando um sistema axiológico que atua como fundamento material de todo o ordenamento jurídico. (SARLET, 2012, p.47).

Os direitos fundamentais como base valorativa (axiologia) estrutura todo o ordenamento jurídico Constitucional tornando-se uma das principais disciplinas como meio para uma efetiva defesa, libertando a sociedade das amarras opressiva do Estado.

Ficando muito evidente a relevância das normas fundamentais mais precisamente após a segunda grande guerra, segundo Sarlet:

[...] formado pelas decisões fundamentais, da ordem normativa, revelando que mesmo num Estado constitucional democrático se tornam necessárias (necessidade que se fez sentir da forma mais contundente no período que sucedeu à Segunda Grande Guerra) certas vinculações de cunho material para fazer frente aos espectros da ditadura e do totalitarismo.

$[\ldots]$

A liberdade de participação política do cidadão, como possibilidade de intervenção no processo decisório e, em decorrência, do exercício de efetivas atribuições inerentes à soberania (direito de voto, igual acesso aos cargos públicos etc.), constitui, a toda evidência, complemento indispensável das demais liberdades. (SARLET, 2012, p.48).

Como vimos é por meio do conhecimento dos direitos fundamentais, ferramenta indispensável à sociedade, que esta se fará efetiva em sua participação democrática e se imporá frente a um governo ditatorial, garantindo assim o acesso à justiça, permanecendo povo livre, engajado em todas as decisões que norteiam seu Estado.

\section{DOS DIREITOS FUNDAMENTAIS}

Os direitos e garantias fundamentais, como expresso em seu Título II da Constituição de 1988, traz a chamada "aplicabilidade imediata" amparada pelo 
artigo $5^{\circ}$ e $\S 1^{\circ}$ da Constituição Federal e consagrada como garantias de eternidade (cláusulas pétreas) pelo artigo 60 e $\$ 4^{\circ}$ da Carta Magna. Dentro deste artigo encontramos direitos fundamentais e outras garantias fundamentais em diversos lugares da Constituição Federal de forma esparsa.

Não há dúvidas que o direito fundamental passa pelo seu melhor momento da história, tendo em vista a sua importância e sua instrumentalidade que está à disposição do técnico do direito, dos parlamentares que elegemos para nos representar e, também, nas mãos do povo, quando unido pela busca legitimada de seus direitos.

Dentro deste viés de que toda e qualquer pessoa é detentora dos direitos e garantias fundamentais, cabe-nos salientar a responsabilidade solidária do Estado e da sociedade, no que tange à educação, tema desta pesquisa. Como assim está elencada na Constituição Federal (BRASIL, 1988) em seu artigo 205 “A educação, direito de todos e dever do Estado e da família, será promovida e incentivada com a colaboração da sociedade, visando ao pleno desenvolvimento da pessoa, seu preparo para o exercício da cidadania e sua qualificação para o trabalho".

Tendo em vista este oportuno momento que nos encontramos, é de salutar importância que todo cidadão e indivíduo na sua formação tenha acesso aos direitos fundamentais pela inclusão desta disciplina na matriz de ensino.

\section{DOS DIREITOS FUNDAMENTAIS HORIZONTAIS}

Ao discorrermos sobre a teoria da eficácia horizontal dos direitos fundamentais, temos que abordar a teoria indireta, que apresenta dois pontos: a) negativa, que proíbe o legislador de editar normas que violem os direitos fundamentais; $b$ ) positiva, que impõe ao legislador que edite leis sobre direitos fundamentais pensando sobre quais delas se adequam às relações privadas.

Dentro dessa teoria a premissa é que os direitos fundamentais causam seus efeitos por meio de um intermédio legislativo, no qual deve o legislador se privar de violar os direitos fundamentais e criar normas que favoreçam as relações privadas.

Outra teoria dos direitos fundamentais horizontais é a teoria direta, a qual os doutrinadores acreditam ser a mais assertiva para o Brasil, já que a desigualdade é tão expressiva em nosso território proporcionando inúmeras injustiças.

$\mathrm{Na}$ teoria do direito fundamental horizontal direto as partes envolvidas devem exteriorizar o respeito ao direito do próximo de forma espontânea, sem a intervenção do Estado/legislativa e respeitando as desigualdades sociais.

Nas relações privadas de cunho público deve-se acima de tudo primar pela eficácia direta dos direitos fundamentais, principalmente para minimizar as diferenças sociais sem mediação de norma legislativa:

Ponto de partida para o reconhecimento de uma eficácia dos direitos fundamentais na esfera das relações privadas é a constatação de que, ao contrário do Estado clássico e liberal de Direito, no qual os direitos fundamentais, na condição de direitos de defesa, tinham por escopo proteger o indivíduo de ingerências por parte dos poderes públicos na 
sua esfera pessoal e no qual, em virtude de uma preconizada separação entre Estado e sociedade, entre o público e o privado, os direitos fundamentais alcançavam sentido apenas nas relações entre os indivíduos e o Estado, no Estado social de Direito não apenas o Estado ampliou suas atividades e funções, mas também a sociedade cada vez mais participa ativamente do exercício do poder, de tal sorte que a liberdade individual não apenas carece de proteção contra os Poderes públicos, mas também contra os mais fortes no âmbito da sociedade, isto é, os detentores de poder social e econômico, já que é nesta esfera que as liberdades se encontram particularmente ameaçadas, como dão conta, entre tantos outros, os exemplos dos deveres de proteção na esfera das relações de trabalho e a proteção dos consumidores. Em tais domínios, manifestam-se, com particular agudeza (como, de resto, em outros casos onde está em causa a tutela de pessoas e grupos socialmente fragilizados e mais vulneráveis mesmo na esfera das relações privadas) tanto as questões ligadas aos deveres de proteção dos órgãos estatais e a sua vinculação às normas constitucionais, quanto a questão da eficácia dos direitos fundamentais em relação aos atores privados propriamente ditos. (SARLET, 2012, p. 323 - 324).

E é dentro deste viés da eficácia horizontal direta que as relações privadas, sejam elas de cunho público ou não, como por exemplo: escolas, clubes e associações, devem ter como premissa nessa relação horizontal o princípio da dignidade da pessoa humana.

Os direitos fundamentais horizontais devem ser, como já mencionado, espontâneos, vislumbrando entre as partes privadas os direitos que cada uma detém, sem que haja uma intervenção estatal para que o direito alheio seja respeitado.

\section{A EDUCAÇÃO NA CONSTITUIÇÃO}

A Constituição de 1988 no seu artigo $6^{\circ}$ já estabelece como direito social o direito à Educação, vejamos: "São direitos sociais a educação, a saúde, a alimentação, o trabalho, a moradia, o transporte, o lazer, a segurança, a previdência social, a proteção à maternidade e à infância, a assistência aos desamparados, na forma desta Constituição". No texto não há especificidade de conteúdo, entretanto, podemos frisar que há um conteúdo de ensino mínimo que deve ser estabelecido.

Desta forma, podemos pontuar de início que a referida educação dever estar ao alcance de todos, isso no que tange especialmente à estrutura mínima de ensino. Sendo assim, esse conteúdo mínimo deve ser oportunizado para todos de forma regular e organizada.

Contudo, em seu artigo 205 a Constituição Federal prescreve que a referida educação visa o pleno desenvolvimento da pessoa, preparo para o exercício da cidadania e a qualificação para o trabalho: "A educação, direito de todos e dever do Estado e da família, será promovida e incentivada com a colaboração da sociedade, visando ao pleno desenvolvimento da pessoa, seu preparo para o exercício da cidadania e sua qualificação para o trabalho". 
Temos desta forma que o direito à educação é um direito fundamental, como nos leciona Tavares (2012, p. 877) “Tem-se, a partir daqui, de compreender um conteúdo da própria educação, como direito fundamental. Não se trata mais de qualquer direito à educação, mas daquele cujas balizas foram construídas constitucionalmente".

Podemos elencar, desta maneira, que o direito à educação deve suprir os anseios constitucionais, visando o desenvolvimento do indivíduo para arcar com suas responsabilidades da qual a própria Constituição lhe incumbe.

Vejamos o que diz o artigo 210 da Carta Magna "Serão fixados conteúdos mínimos para o ensino fundamental, de maneira a assegurar formação básica comum e respeito aos valores culturais e artísticos, nacionais e regionais". Como percebemos no artigo transcrito, há um conteúdo mínimo a ser estabelecido, para assegurar a formação básica comum, respeitando valores culturais.

\section{EDUCAÇÃO, UMA RESPONSABILIDADE DE TODOS}

O processo educativo nas unidades educacionais deve ser visto como uma responsabilidade de todos, desde o núcleo familiar até porteiro, guardas GCMs (Guardas Civis Municipais), professores, alunos, diretores, coordenadores pedagógicos, cooperadores da limpeza, alimentação e funcionários que trabalham nas DREs (Diretoria Regional de Educação), enfim, todos que participarem direta ou indiretamente da comunidade educacional.

Essa conscientização mútua se faz necessária no processo de educação, pois a proposta é a mudança cultural. O aluno desde sua mínima idade (zero idade/ educação infantil), deve observar os valores dos diretos fundamentais no ambiente educacional que o cerca como uma das disciplinas essenciais para o pleno desenvolvimento da criança.

Não só na escola, mas em toda comunidade o papel de educador não se restringe apenas aos professores, é preciso que todos façam parte desta evolução educativa, como por exemplo, os porteiros e os guardas (GCMs), que desempenham uma atividade de segurança, seja segurança individual, como elenca nossa Constituição Federal em seu artigo $5^{\circ}$ caput "Todos são iguais perante a lei, sem distinção de qualquer natureza, garantindo-se aos brasileiros e aos estrangeiros residentes no País a inviolabilidade do direito à vida, à liberdade, à igualdade, à segurança e à propriedade, nos termos seguintes:".

Ou segurança coletiva, como preceitua o artigo $6^{\circ}$ da Constituição Federal "São direitos sociais a educação, a saúde, a alimentação, o trabalho, a moradia, o transporte, o lazer, a segurança, a previdência social, a proteção à maternidade e à infância, a assistência aos desamparados, na forma desta Constituição".

Desempenhando um papel consciente de garantidores da segurança, seja individual ou coletiva, transmitem um dos direitos fundamentais (direito à segurança) aos educandos, propiciando-lhes um ambiente seguro de aprendizagem: 
paço da sala de aula, nem tampouco à relação entre os professores e os alunos. Podemos dizer que todo e qualquer sujeito envolvido na rotina escolar está comprometido com o fazer educativo e compõe com os demais uma grande rede de relações, na qual a ação educativa acontece. (INSTITUTO VLADIMIR HERZOG, 2019a, p. 21).

Segundo o Instituto Vladimir Herzog (2019a, p. 23) "Portanto, essa influência educativa sempre acontece, quer se tenha ou não intencionalidade e consciência dela" do que se entende que todos, sem exceção de nenhum profissional que atue na área educacional, influencia no processo de aprendizagem em comunhão com o núcleo familiar.

O foco principal é a propagação dos direitos fundamentais como cultura, a proposta é a transformação cultural, para que o indivíduo em crescimento possa alcançar o conhecimento necessário para o pleno desenvolvimento de suas atividades políticas, sendo agente transformador na sociedade com o embasamento jurídico necessário para se garantir a justiça.

Para tal feito a pesquisa aponta como ambiente primordial da disseminação dos direitos fundamentais a Educação Infantil, Ensino Fundamental I e II, ou seja, iniciando na Educação Básica, visando a transformação do aluno em agente que engajado na sociedade, é cidadão apto para o pleno exercício da cidadania.

Cabe pontuar que se faz necessário elaborar atividades para os que não puderem participar diretamente da inclusão dos direitos fundamentais nas escolas, porque é indispensável que todos participem da causa.

E essas atividades podem ser elaboradas através de boletins informativos, reuniões escolares em horários flexíveis, murais entre outros, para que todos possam estar conscientizados dos acontecimentos e transformações da própria instituição de ensino e da família, permitindo assim que cada ente familiar possa ser transformado e contribua no processo de desenvolvimento da criança:

\footnotetext{
Esse é um projeto de toda a Unidade, a ser desenvolvido pelo coletivo. Para que isso aconteça, é muito importante assegurar espaços coletivos de troca entre todos os educadores para que reflitam e analisem suas práticas, identificando obstáculos, reconhecendo potencialidades e encontrando formas de garantir a participação de todos os integrantes da comunidade escolar (além dos educadores, os alunos, seus familiares, seus responsáveis, os parceiros da escola etc.). (INSTITUTO...2019a, p. 25).
}

Cabe a todos na unidade educacional desde o seio familiar, interagir, promover, participar, contribuir para a disseminação dos direitos fundamentais para a mudança cultural em que o cidadão capacitado se sinta agente transformador na história.

\section{O INSTITUTO VLADIMIR HERZOG}

Criado com o intuito de celebrar a vida de Vladimir Herzog, jornalista que foi assassinado no período da ditadura entre 1964 e 1985. Vlado, como era conhecido, 
galgou em sua carreira alguns dos mais importantes lugares na impressa brasileira e internacional.

Em 25 de outubro de 1975 foi torturado até a morte, quando foi espontaneamente se apresentar no DOI-CODI (Destacamento de Operações de Informação - Centro de Operações de Defesa Interna) com o fim de responder a um interrogatório.

Em 31 de outubro do mesmo ano, mais de 8 (oito) mil pessoas se reuniram na Catedral da Sé - São Paulo, para um culto ecumênico, com o intuito de celebrar a memória de Vladimir, todos na celebração soltaram um grito de solidariedade, dor e angústia que ecoou no país, iniciando a falência do regime ditatorial.

A família do jornalista abriu um processo no qual o Estado brasileiro foi condenado em sentença judicial, sendo o responsável pela prisão, tortura e morte de Vlado. Assim, em 1978, a família Herzog, o Sindicato dos Jornalistas do Estado de São Paulo, juntamente com outras entidades, cria o Prêmio Jornalístico Vladimir Herzog de Anistia e Direitos Humanos, se tornando este um ícone para o jornalismo no país, sendo o prêmio entregue anualmente e distinguindo mais de 500 (quinhentos) jornalistas, referente às duas temáticas acima.

Mas só em 2009 a família e grupo de amigos de Vlado, criam o Instituto Vladimir Herzog, com vistas a fortalecer e programar atividade/ações que visem os valores da Democracia, Direitos Humanos e a Liberdade de Expressão.

Segundo o Instituto Vladimir Herzog (2009, p. [1])

\begin{abstract}
Almejamos transformar a cultura da sociedade para transformar a própria sociedade. Trabalhamos na formação dos valores do indivíduo, desde os seus primeiros anos de vida, buscando a vivência do respeito à diversidade em todas as dimensões e a consciência de seus direitos e como buscá-los.
\end{abstract}

Todas as atividades do Instituto Herzog são criadas com um viés nos direitos humanos, com projetos educacionais visando valores e respeito à diversidade nos indivíduos.

\title{
EDUCAÇÃO INFANTIL
}

Antes de tecer qualquer comentário, cabe pontuar que tomamos por base o Currículo da Educação Infantil de São Paulo e para as atividades que neste contexto serão propostas adotamos por base o Instituto Vladimir Herzog, dentre outros textos da Educação Infantil que citaremos no decorrer da leitura.

A Educação Infantil é composta por dois momentos importantes na vida das crianças, sendo o primeiro na creche com crianças de até 03 (três) anos no CEI (Centro de Educação Infantil) e o segundo momento na pré-escola com crianças de 4 a 5 anos de idade no EMEI (Escola Municipal de Educação Infantil).

No período de 0 a 3 anos de idade as crianças começam a frequentar o CEI (Centro de Educação Infantil), mais conhecido por creche, nessa faixa etária nem sempre o bebê é reconhecido como sujeito de direito, mas eles têm direitos sim, 
tem direito a serem amamentados, direito a amplo espaço, direito às brincadeiras e de acesso aos brinquedos em qualquer momento, direito a interagir ao meio ambiente e outros direitos.

E apesar do pensamento errôneo de muitos que os bebês não interagem, eles estão em constante interação com o ambiente expressando seus sentimentos através das expressões físicas, comportamentos, inquietações, dentre outras formas de se manifestarem e, modificam o ambiente em que vivem e as pessoas que convivem com eles, ao ponto de mudar o comportamento e a forma de agir dos próprios cuidadores.

Como os educadores vão interagir com as crianças é um dos fatores elencados no livro: "Indicadores de Qualidade na Educação Infantil Paulistana":

A Unidade Educacional deve valorizar o brincar, garantindo vivências lúdicas às crianças e enfatizando sua importância no cotidiano. Os educadores são articuladores das experiências do brincar na escola e preservadores do rico repertório das brincadeiras tradicionais da cultura infantil. Pequenas intervenções nos espaços podem conferir novos sentidos ao brincar, promovendo diversas possibilidades de exploração e potencializando a capacidade investigativa e imaginativa dos bebês e crianças. (SÃO PAULO, SECRETARIA MUNICIPAL DE EDUCAÇÃO, 2016, p. 37).

Ao falar em direitos fundamentais a ser ensinado/transmitido nas CEIs, devemos pensar que os próprios cuidadores também devem partir da premissa de refletir e pensar sobre os direitos dos pequenos, a aprendizagem é mútua, transformará tanto o bebê quanto seus cuidadores.

A Educação Infantil e o Ensino Fundamental neste ponto têm algo em comum, como expressa o Currículo da Cidade de São Paulo: Educação Infantil:

Ambas, porém, possuem um ponto em comum: o compromisso de ser um espaço social para a educação das crianças. Pensando nisso, este Currículo retoma o objetivo de efetivar o direito de bebês e crianças de zero a doze anos a serem respeitadas em sua inteireza e sua integra$\underline{\text { lidade, }}$ ressaltando em ambos os níveis a sua condição de criança e de sujeito brincante. (SÃO PAULO, SECRETARIA MUNICIPAL DE EDUCAÇÃO, 2019, p. 156 - grifo nosso).

No livro "Cuidadores da primeira infância: por uma formação de qualidade" que foi elaborado pela Comissão de Valorização da Primeira Infância e Cultura da Paz sendo organizado por Márcia Álvaro Barr, um dos requisitos de suma importância na aprendizagem e desenvolvimento das crianças é: como este bebê absorverá o ensino transmitido no processo de aprendizagem? Pois esse primeiro contato formará o alicerce para a percepção de todas as outras disciplinas que este sujeito de direito ainda percorrerá: 
A primeira infância é a base para todas as aprendizagens humanas. Estudos demonstram que a qualidade de vida de uma criança entre o nascimento e os seis anos de idade pode determinar em grande parte a sua contribuição para a sociedade na sua vida adulta. Esta fase é o ponto de partida para a construção do laço familiar, de um desenvolvimento harmonioso consigo próprio e com os outros, de uma vida escolar bem sucedida e do fortalecimento das relações sociais, o que proporcionará a formação de um adulto mais preparado para lidar com os desafios do cotidiano. (BARR, 2017, p. 21).

As noções do cuidar e educar são muito expressivas na Educação Infantil, lembrando que a criança nessa fase da vida é totalmente dependente do educador/cuidador, mas não podemos esquecer que mesmo nessa idade de zero (0) a três (03) anos elas não são passivas, muito pelo contrário, constantemente modificam o ambiente e estão sendo influenciadas pelos cuidadores.

\section{CENTRO EDUCACIONAL INFANTIL E OS DIREITOS FUNDAMENTAIS}

Nos Centros de Educação Infantil as crianças dependem muito da mediação dos educadores/cuidadores para toda e qualquer atividade e é portanto nessa mediação que se deve passar o conhecimento dos direitos fundamentais aos pequenos, com um ambiente cujas características trarão notadamente que os direitos fundamentais estão ali para as crianças e ao encontro delas.

A criança desde a mínima idade começará a assimilar os seus direitos e entenderá que o ambiente e a tratativa que recebe dos cuidadores tem um significado e que todo o contexto ali empregado é exatamente para ela e por ela, que como sujeito de direito é respeitada, sendo a protagonista do contexto educacional em que vive, interagindo com as outras crianças e educadores: "Abordagens contemporâneas de cuidado e educação de bebês e crianças até 3 anos de idade apontam para a ideia de uma criança protagonista, que, mesmo muito pequena, é potente, ativa e capaz de se colocar no mundo à sua maneira". (INSTITUTO..., 2019b, p. 15 - grifo nosso).

Nesta fase da vida as crianças se comunicam pelas expressões corporais, faciais e olhares, elas aprendem olhando os educadores e a forma de se tratarem, do respeito entre si e com seus familiares, como serão recepcionados ao chegarem ao Centro de Educação Infantil (creche), a criança nessa faixa etária tem os sentidos muito aguçados e constantemente observará os cuidadores e todos que fazem parte de sua vida cotidiana.

Os educadores junto com toda equipe de colaboradores, sem nos esquecermos dos entes familiares, devem elaborar, sempre que as oportunidades surgirem, a metodologia que mais se adeque à realidade local utilizando-se das ferramentas disponíveis nos Centros Educacionais Infantis. 


\section{ESCOLA MUNICIPAL DE EDUCAÇÃO INFANTIL E OS DIREITOS FUNDAMENTAIS}

Esta etapa da Educação Infantil atende crianças de 4 a 5 anos de idade sendo obrigatória a matrícula e frequência das crianças nas EMEIs (Escola Municipal de Educação Infantil).

O processo de aprendizagem é contínuo e nessa fase as crianças interagem de forma mais complexa, conseguem exteriorizar suas experiências de maneira mais elaborada, ficando para elas muito mais real seu lugar no mundo começando a ganhar a consciência do espaço que ocupam, conseguindo exteriorizar seus sentimentos com clareza e deixando evidente seus desejos.

Neste momento de aprendizagem seu maior desafio será além de explicitar seus desejos e sentimentos, aprender a respeitar os desejos e sentimentos das outras crianças e dos adultos a sua volta. Uma grande oportunidade para o educador ensinar os direitos fundamentais das crianças e como isso repercute diretamente na forma de viver dentro das EMEIs, no seio familiar e na sociedade.

A linguagem verbal que nessa fase começa a aparecer também facilita na aprendizagem e é instrumento fundamental para o educador utilizar na comunicação com os pequenos e se fazer entender, a fala nos pequenos vai ampliar as experiências da aprendizagem possibilitando novos métodos de ensino a ser desenvolvido pela Unidade Educacional e os educadores.

Quando surgir algum conflito entre as crianças, cabe ao educador ter a sensibilidade de intervir no atrito e encorajar os pequenos, que ainda estão aprendendo a se comunicar, a resolverem a questão, claro que o educador terá o papel de nortear as crianças que participarão mais como ouvintes do que falando, contudo, este momento é uma oportunidade ímpar para fazer com que a justiça se sobressaia e incentivar os pequenos a buscarem seus direitos e a superarem seus conflitos de maneira democrática:

\footnotetext{
Ser educador de crianças pequenas exige, portanto, um exercício cotidiano de avaliar seus próprios valores e crenças, pois nessa faixa etária idade as crianças costumam ser "taxadas" e estigmatizadas por características apresentadas em algumas situações. Entretanto, não se pode afirmar que uma criança que frequenta uma EMEI "é violenta", "não sabe escutar" ou "não respeita ninguém". (INSTITUTO..., 2019b, p. 32 - grifos do autor).
}

É normal que haja conflitos até mesmo entre os entes familiares, que alguns se sintam desconfortáveis em algumas situações, isso ajuda na absorção da disciplina, pois todos terão que expor suas dificuldades em aderir à proposta e dialogarem entre si até encontrarem um caminho viável para todos, na maioria das vezes não é uma solução agradável a todos, entretanto, um método que seja viável a comunidade, e isso se chama "democracia", um dos pilares para a evolução da sociedade e norte para a garantia da justiça. 


\section{ENSINO FUNDAMENTAL}

O Ensino Fundamental é dividido em duas etapas, Ensino Fundamental I (anos iniciais) do $1^{\circ}$ ao $5^{\circ}$ ano, com crianças de 06 (seis) anos de idade aos 10 (dez) anos de idade e Ensino Fundamental II (anos finais) do $6^{\circ}$ ao $9^{\circ}$ ano, com crianças de 11 (onze) anos aos 14 (quatorze) anos de idade, período obrigatório em que as crianças devem cursar os respectivos anos.

Nesse período da Educação Básica as crianças já estão mais desenvolvidas e com um potencial de expressar seus sentimentos e desejos com maior clareza, elas conseguem interagir com o ambiente à sua volta e com as pessoas de maneira mais diversificada, nas quais o educador e a família, ambos atuando simultaneamente, devem aproveitar o leque de oportunidades que vai cada vez mais crescendo, para um ensino mais dinâmico e interativo.

A cada ano cursado intensificam-se os ensinos e as tarefas a serem desenvolvidas. Cada vez mais os meios de ensino e aprendizagem se caracterizam pela leitura, escrita e cálculo que claramente são utilizados constantemente no processo de aprendizagem.

\section{ENSINO FUNDAMENTAL I (ANOS INICIAIS) E OS DIREITOS FUNDAMENTAIS}

Neste ambiente com crianças de 6 a 10 anos no Ensino Fundamental I (anos iniciais) o educador paulatinamente deixa de ser a figura central e os pequenos passam agora a ter também os colegas como referência e a cada dia se tornam mais autônomos.

As crianças passam a interagir uma com as outras com intensidade e a se reconhecerem como alunas e alunos dentro da sala de aula com a percepção de que aquele ambiente foi pensado e elaborado exclusivamente para o desenvolvimento das suas aptidões.

Um dos maiores desafios para as crianças nessa fase da educação é o
processo de alfabetização, contudo, a aprendizagem das primeiras le-
tras e do início das leituras oportunizará um campo vasto para que o
professor possa explorar junto aos pequenos e incorporar em várias
atividades as famílias, que ao perceberem o desenvolvimento de seus
filhos se sentem motivadas a participarem dos trabalhos, cabe ao pro-
fessor aproveitar esse momento e engajar os entes familiares para a par-
ticipação em grupo.

Explorar o processo de aprendizagem com a utilização das letras, leituras e primeiros números que serão aprendidos é primordial para se transmitir o ensino dos direitos fundamentais, deve o professor ter a sensibilidade de inserir leituras, desenhos e escritas que versem sobre seus direitos. Lembrando que os métodos aqui apresentados sempre serão subsidiários, devem os colaboradores encontrar o melhor caminho para o ensino sem se esquecerem da sua realidade local: 
Um dos maiores e mais importantes desafios enfrentados pelas crianças nesse primeiro ciclo é o processo de alfabetização, que possibilita ampliar o acesso à cultura e às informações a que todos têm direito na sociedade, contribuindo de forma significativa para a construção da condição de cidadão. (INSTITUTO...,2019b, p. 61).

À medida que os direitos fundamentais forem absorvidos pelas crianças ao vivenciarem suas experiências dentro da própria escola e fora dela, começará o processo de transformação cultural, porque através de suas experiências cotidianas dentro e fora da escola, crescerá o sentimento de pertencimento à Unidade Educacional e do contexto social em que vivem.

Uma proposta de atividade que parece boba, mas que ajuda e dará várias oportunidades para os professores de transmitir conhecimento e valores, é criar um material de "primeiros socorros" e ensinar aos alunos do Ensino Fundamental I o que fazer quando alguém cair da escada, se machucar ao brincar, ou desmaiar, dentre outras inúmeras possibilidades de situações que acontecerão no ambiente escolar.

Os professores podem criar/elaborar atividades em grupo e/ou individuais para aprofundar os conceitos dos direitos fundamentais que mais acharem convenientes ou se apropriar desses momentos para elucidar os conceitos mais difíceis de serem compreendidos entre os pequenos, essas oportunidades são únicas para utilizar a leitura e a escrita, forma principal de manifestação entre as crianças neste período.

Por isso, promover situações em que os alunos sejam convocados a interagir munidos de um objetivo comum (compartilhar saberes, dificuldades, pedir e oferecer ajuda) pode incrementar um processo de construção compartilhada de conhecimento e de atitudes de solidariedade. (INSTITUTO...,2019b, p. 61).

Essas situações são pensadas de maneira a permitir aos envolvidos terem uma nova visão do ponto de vista dos direitos fundamentais com aplicabilidade em suas experiências diárias na comunidade escolar. O intuito das atividades é a consolidação da disciplina e reestruturação das relações pessoais tanto no seio familiar quanto na escola, relações de respeito mútuo com base nos direitos fundamentais.

\section{ENSINO FUNDAMENTAL II (ANOS FINAIS) E OS DIREITOS FUNDAMENTAIS}

Neste momento da Unidade Educacional os alunos do Ensino Fundamental II cursarão a $6^{\circ}, 7^{\circ}, 8^{\circ}$ e $9^{\circ}$ ano, compreendendo alunos de 11 (onze) a 14 (quatorze) anos de idade.

A partir do $6^{\circ}$ ano os professores podem dividir a docência de uma mesma classe, permitindo aos alunos explorarem/entenderem uma determinada disciplina de pontos e olhares diferentes e refletirem sobre a interdisciplinaridade entre as matérias e descobrir como são conexas. 
O início do Ensino Fundamental II é marcado pela presença da interdisciplinaridade, e as correlações entre as disciplinas, o impacto dento da Unidade Educacional, como essa correlação aprofunda o conhecimento e acrescenta valor na disciplina deve ser tratada com frequência no ensino fundamental II:

\footnotetext{
Quanto mais frequentes forem essas abordagens interdisciplinares, maior será a possibilidade de os alunos aprenderem a estabelecer relações para a compreensão de questões complexas.

Elaborar ideias (hipóteses, proposições) acerca dos assuntos tratados na escola e compartilhá-las com os colegas são oportunidades que devem fazer parte da rotina dos alunos com muita frequência. (INSTITUTO VLADIMIR HERZOG, 2019b, p.67).
}

Com a possibilidade de dois professores serem docentes de uma mesma classe, existe a oportunidade de os alunos entenderem a relação dos direitos fundamentais e sua historicidade, permitindo com que os estudantes possam enxergar seus direitos de pontos diferentes, entendendo sua evolução histórica e quais obstáculos seus antecessores tiveram que enfrentar.

Uma boa atividade para os alunos do Ensino Fundamental II apresentada pela Instituição Vladimir Herzog é a criação de um país imaginário dentro da escola, com regras e combinados entre todos da comunidade escolar para vivenciarem na íntegra os direitos fundamentais em todos os aspectos.

Para uma vivência/experiência de todo contexto que está sendo transmitido em sala de aula, experimentar no dia a dia da escola o que foi discutido em sala de aula acarretará uma experiência ímpar para os alunos, oportunizando novos debates em classe e se apropriando dos momentos marcantes para poderem fazer um teatro, uma apresentação, uma cantata, trazendo seus familiares para participarem e interagirem também:

Uma proposta de atividade muito interessante é sugerir aos alunos que definam regras de convivência, direitos e combinados para reger um país imaginário (ou uma escola, uma sala de aula, uma rua). Esse exercício é uma oportunidade de reflexão e discussão que pode contribuir de forma significativa para a compreensão dos direitos de cada um e de todos, aproximando-os das questões inerentes à convivência e à vida em grupo. (INSTITUTO...,2019b, p. 67 - 68).

Discutir essas situações criadas no seio da Unidade Educacional aprofunda o conhecimento dos alunos sobre a temática abordada e traz uma melhor compreensão sobre algumas questões que talvez na sala de aula dificulte o entendimento.

O debate criado fará os alunos absorverem melhor o conteúdo e elaborem um método de convivência no qual seus direitos devem ser respeitados, justificando cada escolha adotada, se responsabilizando pela ideia apresentada, ou seja, o sentimento de pertencimento daquele país imaginário vai crescendo e consequentemente cresce o desejo de lutar, para que esses direitos sejam de fato inseridos na vida 
cotidiana da sociedade. Segundo o Instituto Vladimir Herzog (2019b, p. 69) "As discussões podem incluir a temática da efetivação desses direitos, tanto no que compete ao Estado quanto à responsabilidade de todos para com o direito de todos".

Vale reiterar que todas as propostas de ensino no presente trabalho são subsidiárias, cabendo a todos os profissionais da Unidade Educacional, principalmente os professores, desenvolver a melhor metodologia a ser aplicada considerando as ferramentas disponíveis e o contexto social de cada comunidade educacional.

\section{CONSIDERAÇÕES FINAIS}

Considerando o discorrer de toda pesquisa passando pelo marco da história brasileira e a grande necessidade da aprendizagem das ciências jurídicas em nosso país, com o intuito na formação de políticos e advogados, superamos e chegamos ao objetivo do início da história jurídica em nossa nação, conseguimos a formação de políticos e advogados e, com isso, o objetivo inicial foi contemplado.

Contudo, no presente momento acreditamos que se faz necessária a inclusão jurídica com outro foco, visando à instrução dos conhecimentos mínimos para que todo cidadão possa estar preparado para atuar de fato com a sociedade ao ponto de sentir o pertencimento ao Estado.

Acreditamos que toda essa instrução jurídica deve vir com uma nova roupagem, começando em primeiro lugar com o docente e todos da comunidade educacional, inclusive os entes familiares, pois é preciso que educador e educando se relacionem em um diálogo contínuo de mentes abertas para junto aprenderem e descobrirem novos campos a serem explorados, que possam descobrir em pleno diálogo racional as fragilidades da sociedade que precisam ser sanadas, para o equilíbrio da sociedade, buscando garantir a justiça, acreditando que o alvo é a equidade para um país em pleno desenvolvimento e multicultural.

É salutar que o ser humano em processo de absorção jurídica consiga se desalienar e soltando-se das amarras que o faz submisso a um governo ditatorial, vislumbre nesse processo libertador o seu lugar no mundo e como esse cidadão é de suma importância na participação para a efetivação de seus direitos e da sociedade.

Chegamos à presente consideração que a inclusão jurídica por meio da Educação Infantil e Ensino Fundamental é extremamente importante para o pleno desenvolvimento do indivíduo em formação, desde a tenra idade com a perspectiva de mudança cultural no cidadão, que se bem instruído quanto aos seus direitos e garantias, pode exercer suas atividades (direitos e deveres) de forma efetiva cumprindo seu papel ao que tange a todas as tomadas de decisão que envolve seu país e assim ser participante/ativo na sociedade.

As disciplinas jurídicas elencadas só podem contribuir para o desenvolvimento do cidadão e da sociedade, pois contribuirão para a evolução do ser humano e o pleno exercício de suas aptidões sociais, econômica e política.

Ademais, importa frisar que o conhecimento jurídico propiciará melhores profissionais para o mercado de trabalho, mudando não só a economia, mas a for- 
ma de interagir no mundo e através dele, aprendendo quais são seus direitos e deveres, como também ensinando ao seu rol social do qual participa cotidianamente.

Especialmente viabilizando-se a temática Direitos Fundamentais na matriz da Educação Infantil e Ensino Fundamental exponencialmente crescerá a criança em formação com uma nova cultura e um novo olhar de mundo aprendendo quais são seus direitos e garantias fundamentais, salvaguardado pela Constituição Federal.

Desta forma professor, aluno, entes familiares e todos que colaboram para o funcionamento da escola aprenderão em conjunto uma disciplina que mudará sua forma de agir no mundo, pensar e olhar o próximo.

Como elencado na pesquisa o subtítulo: "dos direitos fundamentais horizontais" frisa o direito fundamental entre particulares sendo respeitado de forma espontânea e o mais importante, sem a intervenção do Estado, pois esta é a proposta na mudança cultural, que o direito de um cidadão seja observado pelo outro sem a mínima interferência do poder estatal.

Tal perspectiva cultural deve ser disseminada e incentivada na sociedade. Olhar o próximo entendendo seus direitos e respeitando-os por livre e espontânea vontade, é sem dúvida alguma, um avanço significativo na evolução cultural de nosso país.

É preciso que cada cidadão entenda seus direitos, busque por eles e percebendo seu lugar na nação, acredite que ele (cidadão) faz parte de cada mudança que acontece e que nesse processo cresça o sentimento de pertencimento, de deveres, de responsabilidades, sentindo-se engajado de fato como sujeito de direito na transformação social, econômica e política da qual faz parte.

\section{REFERENNCIAS}

BRASIL, Constituição da República Federativa do Brasil: promulgada em 5 de outubro de 1988: Disponível em:< http://www.planalto.gov.br/ccivil_03/constituicao/constituicao. htm >. Acesso em: 05 de fev. 2020.

BRASIL, Nações Unidas. Declaração Universal dos Direitos Humanos. Disponível em: < https://nacoesunidas.org/direitoshumanos/declaracao/ >. Acesso em: 14 de mai. 2020.

BRASIL, Senado Federal. Lei n ${ }^{\circ}$ 9.394, de 20 de dezembro de 1996: Estabelece as diretrizes e bases da educação nacional. Disponível em:< http://www.planalto.gov.br/ccivil_03/ leis/L9394compilado.htm >. Acesso em: 18 fev. 2020

BARR, Marcia Alvaro, Org. Cuidadores da Primeira Infância: por uma formação de qualidade. Brasília - DF; Senado Federal; Comissão de Valorização da Primeira Infância e Cultura da Paz, 2017, 193p. Disponível em: < http://www2.senado.leg.br/bdsf/handle/ id/536044 >. Acesso em: 07 de mar. 2020.

COTOMACCI, Gustavo. Estranhos-s no ninho: ensino jurídico e formação docente. Orientador: Prof. Dr. Marcelo Furlin. 2017. Número de folhas 129. Pós-Graduação Stricto Sensu (Escola de Comunicação, Educação e Humanidades) - Universidade Metodista de São Paulo, São Bernardo do Campo. 
FAZENDA, Ivani Catarina Arantes. Integração e interdisciplinaridade no ensino brasileiro: efetividade ou ideologia. 6 ed. São Paulo: Ed. Edições Loyola, 2011. Disponível em: < https://www.pucsp.br/gepi/downloads/PDF_LIVROS_INTEGRANTES_GEPI/livro_ integracao_interdisciplinaridade.pdf >. Acesso em: 15 de jan. 2020.

FRANCO, Fernanda Godinho. O acesso à educação jurídica como meio de contribuir para a formação da cidadania Conteúdo Jurídico, Brasília-DF: 11 jun. 2019. Disponível em: < https://conteudojuridico.com.br/consulta/artigos/53034/o-acesso-a-educacao-juridica-como-meio-de-contribuir-para-a-formacao-da-cidadania >. Acesso em: 18 fev. 2020.

FREIRE, Paulo. Pedagogia do oprimido. 23 reimp. Ed. 17. São Paulo: Ed. Paz e Terra, 1987. Disponível em: < http://www.letras.ufmg.br/espanhol/pdf/pedagogia_do_oprimido. pdf >. Acesso em: 10 de out. 2019.

INSTITUTO VLADIMIR HERZOG (São Paulo). Secretaria Municipal de Educação (org.). Respeito na Escola: 3. ed. São Paulo: Instituto Vladimir Herzog, 2019a. (Respeitar é preciso). Disponível em: < https://respeitarepreciso.org.br/wp-content/uploads/2019/12/ Respeito_na_Escola.pdf $>$. Acesso em: 23 abr. 2020.

INSTITUTO VLADIMIR HERZOG (São Paulo). Secretaria Municipal de Educação (org.). Educação em direitos humanos para todas as idades: 3. ed. São Paulo: Instituto Vladimir Herzog, 2019b. (Respeitar é preciso). Disponível em: < https://respeitarepreciso.org.br/ wp-content/uploads/2019/11/EDH-PARA-TODAS-AS-IDADES.pdf >. Acesso em: 23 abr. 2020.

INSTITUTO VLADIMIR HERZOG (São Paulo). Secretaria Municipal de Educação (org.). Quem somos: São Paulo: Instituto Vladimir Herzog, 2009. Disponível em: < https://vladimirherzog.org/o-instituto/ >. Acesso em: 23 nov. 2020.

OLIVEIRA, Leonil Bicalho de. Acesso à educação jurídica: pela inclusão do ensino jurídico na grade curricular regular. Jusbrasil, 2013. Disponível em: < https://leonilgv.jusbrasil. com.br/artigos/114696517/acesso-a-educacao-juridica-pela-inclusao-do-ensino-juridico-na-grade-curricular-regular > Acesso em: 10 fev. 2020.

SÃO PAULO (SP). Secretaria Municipal de Educação. Currículo da cidade: Educação Infantil - São Paulo, 2019, 224p. Disponível em: < https:/ / educacao.sme.prefeitura.sp.gov. br/wp-content/uploads/Portals/1/Files/51031.pdf >. Acesso em: 25 de mar. 2020.

SÃO PAULO (SP). Secretaria Municipal de Educação. Indicadores de Qualidade da Educação Infantil Paulistana. São Paulo, 2016, 72p. Disponível em: < http:/ / portal.sme.prefeitura.sp.gov.br/Portals/1/Files/25101.pdf >. Acesso em: 28 de mar. 2020.

SARLET, Ingo Wolfgang. A eficácia dos direitos fundamentais: uma teoria geral dos direitos fundamentais na perspectiva constitucional. 11. Ed. rev. atual. Porto Alegre: Ed. Livraria do Advogado, 2012. Disponível em: < https://www.academia.edu/28957456/E_ book_Ingo_Sarlet_A_Eficacia_dos_Direitos_Fundamentais >. Acesso em: 15 de jan. 2020.

TAVARES, André Ramos. Curso de Direito Constitucional. 10. ed. rev. e atual. São Paulo: Ed. Saraiva, 2012. Disponível em: < http://noosfero.ucsal.br/articles/0010/3240/tavares-andr-ramos-curso-de-direito-constitucional.pdf >. Acesso em: 08 de nov. 2020. 